$\begin{array}{ll}\text { le portiQue } & \text { Le Portique } \\ \text { Revue de philosophie et de sciences humaines }\end{array}$

$18 \mid 2006$

Heidegger. La pensée à l'heure de la mondialisation

\title{
Le passé du devenir
}

\section{Geneviève Clancy}

\section{OpenEdition}

Journals

Édition électronique

URL : https://journals.openedition.org/leportique/821

DOI : 10.4000/leportique.821

ISSN : $1777-5280$

\section{Éditeur}

Association "Les Amis du Portique"

Édition imprimée

Date de publication : 1 septembre 2006

ISSN : 1283-8594

Référence électronique

Geneviève Clancy, « Le passé du devenir », Le Portique [En ligne], 18| 2006, mis en ligne le 15 juin 2009, consulté le 20 février 2023. URL : http://journals.openedition.org/leportique/821 ; DOI : https://doi.org/ 10.4000/leportique.821

Ce document a été généré automatiquement le 20 février 2023.

Tous droits réservés 


\section{Le passé du devenir}

\section{Geneviève Clancy}

1 Sans doute faut-il réapprendre à lire les fleuves, la clarté des sources, l'émotion du vent et de l'arbre pour prendre la mesure des effacements et des absences qui font l'obscurité de notre devenir.

2 Qui était le passé ? Non point ses figures mais son «âme » où les mythes nous content un temps de côtoiement entre les hommes et les dieux qui allait nous laisser les plus grandes légendes sur les fonds de l'amour, de la beauté, de la lumière.

3 Là prend sans doute naissance cette douleur de l'irretour qui mène la pensée à penser l'histoire de sa perte et de son écart d'avec ce moment.

4 Aller en quête de l'origine perdue, remonter le cours "de l'homme dans le passé » (selon l'expression soufi) nous paraît être une entrée éclairante, choisie par Heidegger pour pénétrer les enjeux de profondeur historique. La métaphysique se révélera alors comme césure et toute puissance sur quoi s'est fondée l'idéologie de la technique qui est la pensée dominante de l'occident contemporain. Une telle recherche ne pouvait se mener par simple analyse, il lui fallait s'enraciner dans la vision poétique comme dévoilement. C'est l'importance du commentaire de «les hymnes de Hölderlin », la méditation philosophique élit alors la poésie comme mystère et non comme objet.

Le fleuve Rhin du poète est une allégorie du destin rapportée à son origine. Le devenir d'un cours qui passe de sa puissance vitale, majestueuse, à une production d'énergie électrique, du romantisme de sa légende à un marché touristique. La destitution du fleuve mythique en fleuve marchandise par la technique écrit la coupure radicale avec l'origine.

Mais comment renouer avec ce temps?

7 Sur quoi fonder la légitimité d'une philosophie dont la fin serait de prendre la source dans l'initial?

8 Hölderlin dans son Hypérion offre une voie : «la poésie dis-je sûr de mon fait est le commencement et la fin de cette science (la philosophie). Comme Minerve de la tête de Jupiter elle est sortie de la poésie d'un être infini et divin. Et de même à la fin, 
l'inconcevable reflue en elle dans la mystérieuse source de la poésie » (fragment 187 d'Hypérion cité par Heidegger dans le livre sur les Hymnes de Hölderlin).

N'est-ce point ici comme proféré par Hölderlin un sens qui parcourt l'ensemble de l'interrogation heideggérienne? Une quête de l'originaire qui rende l'homme à nouveau témoin-mémoire de ce temps où il restait proche de son essence.

La poésie joue alors le rôle d'une ontologie de ce qui est là, offrant de retrouver les signes perdus.

11 Nous nous permettons de souligner une certaine résonance avec la pensée Soufi dont la langue est poésie et qui selon le philosophe poète Adonis peut : « dire l'invisible », dire ce qui est voilé par ce qui est là.

Il s'agit de la relation entre le sens et l'image. Le sens est voilé par l'image mais l'image est ce par quoi il peut se révéler.

Ainsi l'apparence est nécessaire pour qu'il puisse s'y présenter, au sens de la présence qui se tient derrière son voilé.

Halladj souligne l'unité du sens et de l'image, ce qui permet à l'homme de façonner son identité.

Se trouve également posée la relation entre le langage et l'Être. Dans un entretien Adonis expose la raison pour laquelle selon lui le surréalisme et l'écriture automatique résonnent de la pratique Soufi. Chat'h est l'instant où s'efface la conscience et durant lequel le soufi se met à penser et à écrire. C'est l'état où s'annule la censure exercée par la conscience. Nous sommes au cœur d'une préoccupation de pensée qui situe la langue poétique dans une mise en œuvre du dévoiement de l'unité humaine et de l'infini par l'unité absolue entre le sens et l'image.

Il s'agit d'une libération du joug d'un rationalisme exacerbé qui fait césure entre l'homme et lui-même par l'incapacité de se tenir dans la parole qui parle en lui de l'univers à l'univers.

Adonis ajoutera que « débarrassé du dogme religieux » tout poète est soufi au sens de la méthode de dévoilement de la connaissance et de la quête du sens.

Pour Heidegger la poésie dispose de l'homme, le Dasein est support de la puissance de la poésie.

19 Il nous parait important de souligner que, pour approcher l'essence de la poésie, Heidegger procède à la façon de la théologie négative, comme maître Eckart aborde Dieu en ce qu'il n'est pas, il dit ce que n'est pas la poésie. Elle n'est pas un embellissement du langage, un processus de production du poème. Elle n'est pas l'expression linguistique d'un vécu psychique, mais si elle comprend tout cela, tout cela ne résume pas son essence.

20 Poétiser serait alors dire sur le mode du signe qui rend manifeste. Ainsi la poésie est l'état extrême de nudité aux orages, cette foudre du père (dont parle Hölderlin); la saisir plonge dans l'état du chant. Heidegger opère un dépli des hymnes, il ne les commente pas. Il découvre quel sens caché révèle la poésie quand on la parcourt par l'interrogation philosophique; telles des couches ontologiques qui vont de l'être là à l'Être grâce à la clarté protégée du mot poétique dans le mot et qui fera du langage une " maison de l'Être »; il s'agit de recevoir le signe et de le transmettre.

21 La poésie est l'écho du signe: "le faire signe d'éclair des dieux qui se voile en s'enveloppant dans le mot » (Heidegger, Commentaire d'Hölderlin). 


\section{RÉSUMÉS}

«Le Passé du devenir ». Pour Heidegger, la quête poétique de l'origine perdue est le lieu d'ou l'on peut mesurer les enjeux de l'histoire. Ainsi, de ce point de vue, la métaphysique se révèle-t-elle comme une césure marquant l'avénement de la toute-puissance d'une pensée sur laquelle s'est fondée l'idéologie de la technique, devenue la pensée dominante de l'Occident contemporain.

"The past of the Becoming". For Heidegger, the poetic quest of the lost origin is the locus where one can measure the stakes of history. In such a manner, metaphysics reveals itself as a transition stage that anticipates the advent of an overpowering doctrine on which the "ideology" characteristic of modern technology is founded. An "ideo-logy" that has become the dominant one in the contemporary West.

Para Heidegger, la busca poética del origen perdido es el lugar desde el cual se pueden medir lo que la historia pone en juego. Asimismo la metafísica aparece como una zanja que revela la dominación de un pensamiento en el cual se fundó la ideología de la técnica, que se volvió pensamiento dominante en el Occidente contemporáneo.

"Die Vergangenheit des Werdens". Von der poetischen Suche aus nach der verlorenen Herkunft lässt sich für Heidegger am Besten ermessen was in der Geschichte auf dem Spiel steht. Aus dieser Sicht aus kann man die Metaphysik wie eine Art Zäsur, ein Aufatmen inmitten eines Verses empfinden. Sie sei der Ausdruck eines allmächtigen Gedankengutes, auf dem sich die Ideologie der Technik fundiert.

\section{AUTEUR}

GENEVIÈVE CLANCY

Geneviève Clancy, professeur de philosophie esthétique à l'Université de Paris (I) Sorbonne et poète est décédée en octobre 2005. Ce dossier est consacré à sa mémoire. 
Parmi ses ouvrages, l'on peut citer Esthétique du devenir (1999), Vent des présences (2002) et Les Cahiers de la nuit (2004). 